\title{
Directions of intentionalities in special needs education in mathematics
}

\section{Anette Bagger ${ }^{1}$ (D) $\cdot$ Helena Roos ${ }^{2}$ (D) $\cdot$ Margareta Engvall $^{3}$ (D)}

Published online: 29 April 2020

(C) The Author(s) 2020

\begin{abstract}
This article builds upon a systematic review of 53 articles in international research journals and makes three main contributions. First, it develops a method for identifying motives, values, and assumptions in research by analysing segments of text in journal articles. Second, it represents a reflective account of research within the field of mathematics education. Third, it captures the ongoing directions of intentionalities inherent in the diverse field of special education mathematics and, thereby, some of the characteristics of the core issues in this field. Three directions of intentionalities were identified: towards teachers and teaching competence, towards enhanced mathematical achievement, and towards every student's learning. The results indicate that each direction has specific limitations and potentials. In order to improve special education mathematics, we recommend that researchers and practitioners remain broadly informed and involved in all three directions of intentionalities.
\end{abstract}

Keywords Systematic review · Directions of intentionalities · Special needs education in mathematics

Anette Bagger

anette.bagger@oru.se

Helena Roos

helena.roos@1nu.se

Margareta Engvall

margareta.engvall@liu.se

1 Faculty of Humanities and Social Sciences, School of Humanities, Education and Social Sciences, Örebro Universitet, 70112 Örebro, Sweden

2 Faculty of Technology, Department of Mathematics, Linnaeus University, 35195 Växjö, Sweden

3 Department of Behavioural Sciences and Learning, Faculty of Educational Sciences, Linköping University, 58183 Linköping, Sweden 


\section{Introduction}

Research and practice are continually looking for ways to support students in need of special education in mathematics. Research concerning this quest is situated not only in mathematics education but also in fields such as special education, psychology, sociology, teaching, and learning. The research field of special needs education in mathematics (SEM) is highly diverse in its underlying assumptions (Scherer, Beswick, DeBlois, Healy, \& Moser Opitz, 2016). This implies the involvement of a variety of theoretical assumptions, methodological perspectives, contexts, policies, kinds of students and schools, and so on. Furthermore, SEM research is directed towards such areas as different areas in mathematics, levels of achievement, psychological conditions, methods for teaching and learning, and digital tools (Bagger \& Roos, 2015; Magne, 2006; Schmidt, 2016; Scherer et al., 2016). While SEM research is a diverse and interdisciplinary branch of the social sciences, a common core of SEM research is the interest in the challenge of teaching and learning in mathematics and what factors act as obstacles or opportunities in the learning process for students in need of support. However, labelling mathematics teaching and learning as challenging also defines our own assumptions and positioning as researchers. We draw upon Halai, Muzaffar, and Valero (2016), who stressed that research is not neutral or value free, and at the same time as research communicates and explores a problem, it also contributes to the problem itself and exerts power. Although Halai et al. (2016) examined the rationalities in research and the (deficient) multilingual learner, the foundations in the research at hand, the reason to explore a potentially marginalised group of students and the following effects of power, is similar. Therefore, we argue that a recognition of values and assumptions made in our and other research on SEM-students is necessary. We agree with Halai et al. (2016), who stresses:

This double effect of power in research allows us to evidence that the theoretical and methodological choices of research, educational or otherwise, are not value neutral. Rather they are built on assumptions about what is valued as knowledge and, therefore, what are valorized as approaches and frameworks for the generation of knowledge. (Halai et al., 2016, p. 281)

Therefore, the value assumptions made in the present article need to be presented in the introduction and then reflected upon in the discussion. This article derives from Skovsmose's (2016) theory of intentionality and interpretation of meaning, which is 'structured by economic, political, cultural, and discursive factors' (p. 411) and is expressed through 'opportunities, imaginations, visions, hopes, aspirations, as well as in terms of obstructions, fears and frustrations' (p. 417). We understand these interpersonal and intrapersonal phenomena to be underpinning value assumptions made in research, which supports our claim that there is no such thing as value-free research. Furthermore, value assumptions are understood as governing possible actions and research into how to best support learning in mathematics. Scherer et al. (2016) explored how research can support practice to assist students in need of special education in mathematics, claiming: 'There is need for more evidence-based research in the field of inclusive mathematics classrooms' (p. 19). An important facet of the foundation of evidence is how the knowledge itself is generated in research. One example of this is Roos (2019), who analysed the definitions and roles of inclusion in mathematics education research and showed that inclusion is both used as an ideology and a way of teaching. These ways of using inclusion are usually treated separately and independently from each other, which 
influences both research and practice concerning the implications of working with SEM in inclusive classrooms.

In two earlier projects, the authors of the present article explored how research conceptualises the student in need. They also identified a prominent difference in ontological views, namely, that special education journals contained a categorical view on the learner, while journals on mathematics education emphasised and conceptualised the students in a highly relational way (Bagger \& Roos, 2015). Also, in an exploration of the policy of meaning in a Nordic research sample, assumptions regarding students' normalisation, the effectiveness of teaching, and the teachers' responsibility for supporting and stimulating students' development through high quality in teaching emerged as core assumptions, results, and conclusions regarding what is important in SEM (Bagger, Roos, \& Engvall, 2018). Accordingly, our interest in identifying and investigating the directions of intentionalities of SEM in research began at the intersection between the need for evidence on what SEM is and how to work with SEM in inclusive classrooms. We emphasise the context of special needs education in mathematics, as positioned at the intersection between mathematics education and special education, which we understand as constituting a research field in its own right. The research produced in this field contributes to directions of intentionalities of the research field, which might be unravelled through value assumptions inherited in statements that build up the body of research. This approach has the potential to illuminate epistemological and ontological underpinnings in the field of SEM through the collective meaning making expressed in research texts.

There is no consensus regarding what identifies students in need of special education (Bagger \& Roos, 2015; Heyd-Metzuyanim, 2013; Scherer et al., 2016). Accordingly, the conceptualisation of SEM and SEM students depends on national steering documents, approaches to teaching and learning, and how mathematics and learning difficulties are understood, as well as on the discipline involved and the field of research (Scherer et al., 2016). Usually, these issues are not fully explained or mapped out by research. However, researchers who aim to support the teachers' efforts to support students must be aware of underlying value assumptions. Accordingly, the aim of the present study was to explore directions of intentionalities in current SEM research. Following from this, we have sought to explain the processes of generating knowledge and how these are connected to power relations in society (see, e.g., Scotland, 2012). This was done by first identifying segments of texts that expressed the causes, goals, and solutions of challenges in mathematics teaching and learning. Second, we explored the underpinnings of these depictions in regard to the value assumptions that are made. Following this, we reported directions of intentionalities and discussed them in terms of challenges and opportunities for further research.

\section{Methodology}

In this section, we present our own positioning and value assumptions and how we understand what research texts are and how they work as subjects in the world. This is followed by a section on how we define the theoretical concept of direction of intentionality and how we have operationalised it through interpretative thematic content analysis. 


\subsection{Positioning of our own value assumptions}

Our understanding and point of departure is that nothing can be completely captured by one individual's understanding; therefore, different ideas, perspectives, theories, and beliefs are needed in order to present a more complete representation of a phenomenon. This affords individuals the possibility to obtain affirmation, to reorient, or to reflect on their own understanding. Our intention is to offer research that-although filtered through our own epistemological and ontological value assumptions - provides an understanding of the process of generating knowledge and directions of intentionality in research. As researchers, we are situated in a Nordic and Swedish research context of SEM. In our research, we have used different research approaches, such as Response to Interventions as well as epistemological, discursive, and sociopolitical approaches to the challenges associated with teaching and learning. Our focus has been on teachers, students, and the education system in relation to learning mathematics. We tend to lean towards ethnography-influenced approaches where the insider's perspective is in focus, understanding the student in need as someone who is '...in need of special education in mathematics in order to emphasise the social aspect. The word in is here of great importance. The student is in need, not with needs' (Bagger \& Roos, p.34). Our research leans towards a combination of critical methodology and interpretivism in which reality is understood as socially constructed and knowledge is understood as relative and as generated through meaning and affected by the specific time, history, policy, and culture.

\subsection{Theoretical underpinnings}

Regarding what a text is, our point of departure derives from discourse theories, implying that texts are simultaneously mediating meaning and being mediated through social practices of meaning making (Norris \& Jones, 2005; Scollon, 2001; Scollon \& Scollon, 2009). Thus, discourse is simultaneously represented in practice and reproduced by it, and it is constantly and collectively produced and transferred through time and place by mediating tools and actions (Scollon, 2001). Furthermore, discourses are situated in and shaped through historical, political, cultural, economic, and discursive circumstances (Scollon, 2001). In summary, we understand SEM research as being collectively produced through the discursive mediation of meaning between several social practices, such as the practices of collaborating, observing, reading, writing, analysing, and reporting research and throughout systems of review and editing. This is situated in the present but also shaped by history. Hence, we approach the researched texts as accounts of discourse that are both mediating and mediated by intentionalities in SEM research.

Skovsmose (2016) stressed the importance of investigating the intentionality of interpretation of meaning because mathematics education researchers' understanding of, for example, what is 'good' or 'desirable' will affect interpretations in research: 'Intentionalities can be formed by possibilities as well as by obstructions' (Skovsmose, 2016, p. 9). Considering the earlier reported diversity of SEM in research and the range of who SEM students are, even more urgent questions are what the challenges are and how these challenges should be met. Drawing on Skovsmose's (2016) theories about intentionality of interpretation of meaning, we derive an understanding that intentionality is situated in real life and, therefore, that intentionality directs action and thinking. Skovsmose (2016) stressed that there is a paradox built into the concept of intentionality, which depends on the fact that intentionalities are both socially and personally structured, leading to methodological complexity. Because writing texts is 
highly central in the performance of research, we are aware that directions of intentionality are, in themselves, social fabrications at the same time as we are participating in socially fabricating research. We explore the direction of intentionality by starting the analytical procedure with a selection of text segments deriving from different articles. We understand these segments and how we arrange them as social fabrications regarding SEM itself.

\subsection{Method of selection}

In order to explore directions of intentionalities in current SEM research, we selected articles that focus on challenges in mathematics teaching and learning. The first criterion for selection was studies that dealt with SEM, so the keywords in the search for articles were 'special' and 'mathematics'. The rationale behind this choice derives from insights from previous searches in which we also used other keywords, such as disabilit*. This time, we were interested in the teaching and ideas of support and meaning making regarding SEM in a broad sense, so we did not include disabilit* in our search. In addition, this would have included the field of disability studies to a high degree, whereas at this time, we were aiming more at the educational division of SEM. Also, students with disabilities will be captured by the keyword special, albeit with more emphasis on the support given. These keywords limited the search to research written in English. The second criterion was to find recent research articles, so we applied a time limit of 2015-2017.

The purpose of this delimitation was to provide a current, actual, and here and now snapshot of the meaning making. Because the search was conducted in April of 2017, the actual search was for articles from January 2015 until the end of March 2017. A third criterion was to find high-quality articles, so we decided to search for publications from peer-reviewed journals only. Because special education is a multidisciplinary field, it was important to use a wide scope of databases in order to capture a variation of fields, disciplines, and methodologies and to allow for the crossing of boundaries. The Scopus, ERIC, and MathEduc databases were chosen because they contain SEM research. Because Scopus covers many kinds of research, we restricted our selection to social sciences. ERIC is a database that covers a broad range of topics within the field of educational research; here, we also added elementary education as a criterion and linked to the full texts of the articles because this was an option when searching in this database. The MathEduc database gave us the opportunity to reach the deeper aspects of mathematics education. Therefore, we did not restrict the range of fields because the selected database itself and the keyword 'special' already provided this limitation.

Initially, the search resulted in 229 hits. Despite our limitation to peer-reviewed journal articles in the databases, many of the papers were classified as reports or book chapters, and there were also several duplications. After dealing with these, 82 articles remained. Finally, after reading the abstracts, 29 articles out of the 82 were excluded in the last step of the selection. Some of these were excluded due to irrelevant content, such as not dealing with SEM, others because of overlaps we had not noticed before. In the end, 53 articles spread over a wide range of fields, disciplines and methodologies were selected (see Table 1 for an overview of the search process regarding the number of hits in the database search).

The above process resulted in the selection of articles from a variety of research fields and research journals. The following fields are represented: education and/or technology (e.g., British Journal of Educational Technology); education and learning (e.g., Issues in the Undergraduate Mathematics Preparation of School Teachers); special education (e.g., Journal of Research in Special Educational Needs, International Journal of Inclusive Education); 
Table 1 Outcome of the search in each database reported in number of hits, number of identified articles, and number of articles used for analysis

\begin{tabular}{llll}
\hline Database & $\begin{array}{l}\text { Number of articles in the result } \\
\text { lists }\end{array}$ & $\begin{array}{l}\text { Number of identified } \\
\text { articles }\end{array}$ & $\begin{array}{l}\text { Number of articles selected for } \\
\text { analysis }\end{array}$ \\
\hline Scopus & 124 & 44 & 21 \\
ERIC & 60 & 32 & 32 \\
MathEduc & 45 & 6 & 0 \\
Total & 229 & 82 & 53 \\
\hline
\end{tabular}

mathematics teaching, learning, or education (e.g., Journal of Mathematical Behavior, ZDM: The International Journal on Mathematics Education); and sociology and psychology (e.g., Journal of Early Adolescence, Developmental Psychology).

\subsection{Framework for analysing directions of intentionalities}

Skovsmose's (2016) idea about the directions of intentionality is a mathematics educationsituated critical theory paying attention to what contributes to obstacles and opportunities in the learning process, which is also the core interest in SEM research. In addition, the theory is discursive in nature and allows for an investigation of the epistemology and ontology of SEM in research. Exploring and interpreting how value assumptions emerge in relation to where difficulties lie, to how solutions might be found, as well as to why support is desirable makes it possible to assemble directions of intentionalities. When using values, we draw on Ernest (2016), who stated:

I argue that values are indicated by preferences expressed and choices made in terms of beliefs and underlying frameworks. The initial choice of the framework of absolutism and its underlying assumptions is not forced upon us by necessity. Once this choice is made a consequence is that mathematics is ethics-free and largely values-free. (Ernest, 2016, p. 189)

Drawing on this, we argue and depart from a blend of critical epistemology and interpretive methods in which value assumptions in research build the foundations for the choices that are made and the conclusions that are drawn. These value assumptions are, in turn, shaped by power relations and socially constructed. In that way, value assumptions shape the reporting of research and the collective meaning of what knowledge is, what reality consists of, and what is important or desired as an outcome (see, e.g., Scotland, 2012). By value assumption, we mean the underlying beliefs about what is valued and what is not valued. This could be seen, for example, through the precedence of frameworks and interpretations and by analysing processes of research. According to our understanding, these value assumptions are generated by social and positional power in society and in research, as well as by individuals' personal understandings and experiences. We also depart from Skovsmose (2016) in our understanding of what constitutes a value assumption and what constitutes a value assumption's contribution to meaning. Meaning is the way in which knowledge is generated and governed, and searching for 'opportunities, imaginations, visions, hopes, aspirations, as well as in terms of obstructions, fears and frustrations' (Skovsmose, 2016 p. 417) captures the directedness of intentionalities. We claim that these opportunities, imaginations, visions, hopes, aspirations, obstructions, fears, 
and frustrations are represented through the value assumptions that are made. We draw on Skovsmose (2016) regarding how we understand meaning making within mathematics education as multifaceted and complex:

However, mathematics education does not simply operate within a straightforward referential and use-oriented duality. Here, one finds suggestions for interpreting meaning that combines a variety of ideas and assumptions. (Skovsmose, 2016, p. 414)

It is important to note that we did not analyse articles as separate pieces of research but rather as segments of texts from different articles in relation to each other. In other words, text from one article was coded and put alongside other similar statements and at the same time taken out of its original research context.

The purpose of doing this was to provide a 'here and now' snapshot. A snapshot of research has the potential to display the current state of affairs instead of generalising about trends over time as something stable and prevalent in research. This is connected to our understanding that a snapshot can display a picture of research to learn from, reflect upon, oppose, or agree with. This could enable researchers to clarify their own positionings, get confirmations, shift positions, and/or heighten their awareness of what they take part in and contribute to in terms of social epistemologies. Completing this with additional snapshots in the future might reveal shifts and nuances in the landscape of meaning-making.

The possibility of capturing these snapshots was enhanced by first selecting sections of text in articles that concerned SEM. Typically, this generated three to five longer sections consisting of one to four sentences. The sections had to be long enough to communicate and carry meaning making regarding SEM. These sections were retrieved mainly from the introduction (including purpose), methodology, results, and discussion parts. Thereafter, we selected shorter segments from these sections, and in which opportunities, imaginations, visions, hopes, aspirations, obstructions, fears, or frustrations were expressed. It was on these shorter segments - usually one sentence or sometimes part of a sentence - that the actual analytical work was performed.

\subsubsection{The analysis process}

Table 2 shows examples of the first analytical steps. We selected segments of texts that expressed opportunities, imaginations, visions, hopes, aspirations, obstructions, fears, and frustrations regarding SEM (1a). We then coded the value assumptions expressed in the segments (1b).

The next steps in the analytical procedure are shown in Table 3. The first step was to collect the coded value assumptions into themes (2a). For example, many sections dealt with the students' improved, potential, or desired development, while others dealt with the role of the teachers or schooling as part of society. The themes were given names by using explanatory paraphrasing of the coded content. For example, a theme could be 'teachers' role in student development'. Finally, we explored connections between themes (3b), which generated directions of intentionalities (3).

The findings are elaborated on and explored as narratives in the results section. In summary, we have approached segments of texts as mediational means between social practices of discursive meaning making, in other words, as accounts of discourse that have the potential to reveal intentionality. 
Table 2 Examples of selected segments (1a) and the interpreted value assumptions in these (1b)
1a: Examples of segments containing opportunities,
1b: Interpreted value assumptions
imaginations, visions, hopes, aspirations, obstructions,

fears, and frustrations

'Post-intervention, the teachers reviewed this stance and affirmed that a deeper understanding of children's mathematical thinking provided a more secure knowledge base for instruction'. (Moscardini, 2015, p. 37)

'... recommendations for how mathematics teacher educators might more effectively prepare prospective teachers for the questioning and answering stages of mathematics consultations'. (Van Ingen, Eskelson, \& Allsopp, 2016, p.73)

'... enhancing special education students' mathematics fact knowledge'. (Bakker, Van den Heuvel-Panhuizen, \& Robitzsch, 2016, p. 633)

'... deaf and hard-of-hearing (DHH) students in different educational settings compared with those of hearing students'. (Mekonnen, Hannu, Elina, \& Matti, 2016, p. 345)

'... current special education policies and college practices in Mumbai do not prepare students with math learning disabilities with the math knowledge that they need to succeed in post-secondary mathematics'. (Eichhorn, 2016, p.75)

'One factor that may contribute to these effects is societal stereotypes of Australian Asian and Aboriginal students, which may bias teachers' evaluations and influence student outcomes'. (Dandy, Durkin, Barber, \& Houghton, 2015, p. 60)
Value assumptions that teachers' knowledge about students' thinking is at the core of instruction processes

Value assumptions that teachers' knowledge about instruction needs to be strengthened, which in turn motivates teacher training and change

Value assumptions that factual knowledge needs to be enhanced among special education students

Value assumptions that deaf students have specific educational needs compared with hearing students

Value assumptions that students' opportunities to learn mathematics are connected to progress in higher education

Value assumptions that investigating sociodemographic markers is important because they bias teachers' judgement and students' success in learning

Table 3 The constructed themes (2a) and the exploration of connections between themes (2b) into directions of intentionality (3)

\begin{tabular}{|c|c|c|}
\hline 2a: Themes & $\begin{array}{l}\text { 2b: Connections between } \\
\text { themes }\end{array}$ & 3: Direction of intentionalities \\
\hline $\begin{array}{l}\text { Teachers' knowledge } \\
\text { Teachers' training } \\
\text { Teachers' understanding } \\
\text { Teachers' educational } \\
\text { approach } \\
\text { Improvement of the } \\
\text { themes above }\end{array}$ & $\begin{array}{l}\text { Connection between themes as the promotion of } \\
\text { readiness to provide opportunities to learn for } \\
\text { students }\end{array}$ & $\begin{array}{l}\text { Direction of intentionality towards the } \\
\text { teacher and teaching competence }\end{array}$ \\
\hline $\begin{array}{l}\text { Students' development } \\
\text { Students' achievement } \\
\text { Students' knowledge } \\
\text { Testing of knowledge } \\
\text { Interventions to improve } \\
\text { the themes above }\end{array}$ & $\begin{array}{l}\text { Connection between themes as promoting students' } \\
\text { knowledge by focusing on achievement. }\end{array}$ & $\begin{array}{l}\text { Direction of intentionality of enhanced } \\
\text { mathematical achievement }\end{array}$ \\
\hline $\begin{array}{l}\text { The outcome of } \\
\text { educational practice } \\
\text { regarding: } \\
\text { Organisational structures } \\
\text { Policy of education } \\
\text { Equity } \\
\text { Democracy }\end{array}$ & $\begin{array}{l}\text { Connection as the sociopolitical consequence of } \\
\text { schooling and its impact on ethics and democracy }\end{array}$ & $\begin{array}{l}\text { Direction of intentionality towards } \\
\text { every students' learning }\end{array}$ \\
\hline
\end{tabular}




\section{Directions of internationalities in SEM research}

Segments of texts from all 53 articles contributed to the analysis (e.g., see Table 2). The total selection of articles is given in "Appendix". Of the 53 articles, text examples from 36 articles were sufficient for presenting the results and are thus included in the list of references to this article. Text from one article could be represented in themes contributing to all three directions. In this way, relations between themes were emphasised as directions inherited in value assumptions that define, regulate, govern, produce, and reproduce SEM in research. Therefore, the directions are not to be understood as a categorisation of kinds of articles or research but rather as social meaning making in SEM research as a field. These directions are produced according to the analytical framework, and, as such, they rely on an interpretive analytical procedure.

The directions are as follows: direction of intentionality towards the teacher and teaching competence, direction of intentionality towards enhanced mathematical achievement, and direction of intentionality towards every student's learning.

Each direction is introduced by specifying what themes and what kinds of connections between themes represent the direction. This is followed by a review of the segments found and their value assumptions. Finally, we summarise the contents of the directions.

\subsection{Direction of intentionality towards the teacher and teaching competence}

The themes that generated this direction were teachers' knowledge, teachers' training, teachers' understanding, and teachers' educational approach. This direction was framed mainly by connections between the themes concerning teachers' understandings, ability, knowledge, and approach, which in turn affect instruction, support, and teaching of students in need of support. For example, if knowledge is lacking and interventions do not succeed, teachers are often described as not being ready, but with the right training or knowledge, they will be. The social fabrication contributes to the valuing of teachers' competence. The text segments included in these themes express value assumptions that increased teacher competence is necessary for the SEM students' learning of mathematics. By teacher competence, we refer to the various ways that texts depict teachers' competencies, approaches, etc., as needed in order to be ready to teach all kinds of students. For example, assumptions are made in several segments that it is crucial to enhance the knowledge base for teachers regarding students in need of support or with learning disabilities (e.g., Hinton, Flores, Burton, \& Curtis, 2015; Hunt, Valentine et al., Hunt, Valentine, Bryant, Pfannenstiel, \& Bryant, 2016; Jitendra, Nelson, Pulles, Kiss, \& Houseworth, 2016; Moscardini, 2015; Van Ingen et al., 2016). We interpret this as meaning that the themes are about teacher quality, and the connections between themes suggest a 'higher' purpose, namely, the reassurance of providing opportunities to learn for all students in mathematics classrooms. By providing opportunities to learn, we refer here to teachers' possibilities to offer all students high-quality teaching, which is supposed to be secured through increasing the teachers' knowledge about the students in need. This implicitly indicates that there is a social fabrication of meaning concerning students in need of support as not getting high-quality teaching at a satisfactory level. In addition, this lack of support depends on the teacher. The role of teacher assistants is also assumed to be essential for the implementation of inclusive practices, which are also valued similarly to equity. Teachers are found to give motives to this importance when they say that the teacher assistants reduce stress and workload (Radford, Bosanquet, Webster, \& Blatchford, 2015). 
Further, there were connections between themes about teachers' professional development and their ability to meet students' educational needs in mathematics. Professional development is valued through this connection, and teacher training is assumed to facilitate progress. Thus, progress is explicitly connected to teachers' competence to perform mathematics consultations through training and teacher preparation (Murphy \& Marshall, 2015; Van Ingen et al., 2016). The ability to meet the needs of the student demonstrating difficulties is valued and motivates the importance of teachers' competence to give high-quality and adapted instructions to students (Hunt, Valentine et al., 2016). We interpret this as contributing to a value assumption that teachers with adequate competence can support and help students demonstrating difficulties overcome the difficulty through high-quality instruction. Furthermore, this aspect of teacher competence is not only connected to development but also to silent professional knowledge and quick spur-of-the-moment decisions (Hunt, Valentine et al., 2016). These decisions demand deep knowledge of the development of understanding in mathematics, which is knowledge that is valued. It is also assumed to be important that educators are aware of and adopt practice research findings for more effective pedagogies for every learner (Kalambouka, Pampaka, Omuvwie, \& Wo, 2016).

Segments of texts regarding corrections and development of learning environments and instruction in order to meet students' needs make an assumption of improved learning through improved teaching. For example, some segments have explored the role of cognitively guided instruction (Moscardini, 2015). Improving teaching is a process connected to the teachers' knowledge and understanding of mathematical development and the individual student's knowledge. Here, the assumption behind building knowledge is that teaching demands that the teacher have specific knowledge of the many factors that underpin the decisions made in teaching (Hinton et al., 2015; Hunt, Valentine et al., 2016). Inclusion is valued, and specific knowledge is assumed to be needed in order to make relevant adaptations for enabling an improved learning process for all students (Hunt, Valentine et al., 2016; Kalambouka et al., 2016). A text segment in Powell (2015) makes similar assumptions regarding pre-service educators' development of pedagogical content knowledge. That segment values the importance of skills in mathematics and computation. Pre-service teachers who had a high knowledge and understanding of mathematics content also described their teaching as less procedural and expected to have a better outcome compared with a model with lower expectations and procedural teaching (Hinton et al., 2015). Several text segments reached similar conclusions regarding adaptations that are valued, preferable, or used by teachers. One example of this is the following text from Hunt, Valentine, et al. (2016):

Teachers added visual, kinaesthetic, or verbal cuing to provide connections to concepts, altered contexts of scripts and tasks to connect to students' life experiences, and changed tasks and pedagogy to relate to the informal understandings of the mathematics expressed by students. (Hunt, Valentine et al., 2016, p. 86)

One text segment pointed out an overlooked aspect of supporting students in need of support, namely, the matter of managing and working effectively with additional adults in the classroom (Radford et al., 2015). Hence, there is a value assumption that, in order to work effectively with students in need of support, collaboration in the mathematics classroom needs to be well planned. To conclude, the connections between themes indicate directions of intentionalities towards teachers and teaching competence. The directions display different 
aspects of teachers' competence discussed in research texts and how these aspects are valued as preconditions for teaching and learning in mathematics, with a focus on SEM.

\subsection{Direction of intentionality of enhanced mathematical achievement}

The themes that generated this direction were students' development, achievement, and knowledge and testing of knowledge. The themes framing this direction held the value assumption that there is an expected achievement and that development and knowledge are connected to assessing such achievement. This is often situated in relation to curriculum goals, and achievement consists of knowing mathematics. We identified this mainly through exploring connections and patterns between and within themes concerning students' achievement, testing, and knowledge. An expected achievement in mathematics then becomes the motive for teaching approaches, adaptations, or interventions. Norms and values about achievement and knowledge often constitute the strategy for selection mentioned in these themes and are central in conclusions drawn.

Text segments in themes that constitute this direction describe specific methods that improve student achievement in different content in mathematics, such as multiplication or division. These segments focus on specific knowledge like procedural, declarative, and conceptual knowledge among students (e.g., Bakker et al., 2016; Fien et al., 2015; Hunt, Valentine, et al., 2016). One text segment explored the use of schemes to help two students with learning disabilities to learn concepts related to fractions. The schemes promoted and trained reflection of actions and outcomes, and the text highlights the fact that the students did not perform differently to peers without learning disabilities (Hunt, Tzur, \& Westenskow, 2016); this reveals value assumptions that the students with learning disabilities were somehow different in achievement. Other text segments of texts investigated methods and tools used in instruction, such as the use of visual representations, which improved the ability to solve word problems (Jitendra et al., 2016). Some of the segments concerned expected achievement in relation to interventions directed towards specific groups of students, such as students with visual or hearing impairment or complete deafness (Depountis, Pogrund, GriffinShirley, \& Lan, 2015; Marschark, Shaver, Nagle, \& Newman, 2015; Mekonnen et al., 2016); this indicates a value assumption of achievement in mathematics for students with disabilities. Another example of this assumption is a specific method (the magic finger touch) mentioned in a segment, which was proven to be an efficient method for learning multiplication for deaf students (Thai \& Yasin, 2016). Here, not only value assumptions of achievement in relation to disability were visible but also achievement in relation to a specific content and the value of reaching an expected mathematical achievement through effective methods. Other similar segments of texts (Hunt, Valentine et al., 2016) are directed towards designed interventions and how adjustments in interventions result in improved achievement, but not in relation to a specific disability (Scammacca, Fall, \& Roberts, 2015; Hunt, Valentine et al., 2016; Gunarhadi, Anwar, Andayani, \& Shaari, 2016).

Connections between themes concerning interventions and student behaviour indicated value assumptions regarding the desired effects on students' achievement from interventions and teaching methods. One example is in a text segment from the 'Check, connect and expect' intervention, in which students are coached according to a model (McDaniel, Houchins, \& Robinson, 2016), which is motivated by the value assumption that the coaching by a model supports learning. Another example is a segment from a 
study that attempted to improve problem-solving skills via a specific kind of instruction among students with behavioural or social difficulties (Peltier \& Vannest, 2016). There, value assumptions showed that these students require a specific intervention in order to reach the expected achievement.

Some text segments originate from technology-based interventions with the aim of reaching expected achievement. For example, computer games were used to accelerate math learning in reasoning as well as knowledge in multiplication and division for students who have, or are at risk of developing, math difficulties (Bakker et al., 2016; Fien et al., 2015). These segments of texts imply value assumptions of accelerated learning via technology. Technology was also connected to coaching in the form of an avatar to strengthen students' self-perception and confidence (Kim, Thayne, \& Wei, 2017). This avatar contributes to the process of selfperception and confidence, which is supposedly higher in the case of the average student. Hence, self-perception and confidence are core value assumptions that are expected to have an impact on students' achievement.

Investigation of cognitive functions, deviation from standards, and connection to the development of various mathematical skills are also examples of expected achievement being valued in segments of research texts (Calderón-Tena, 2016). According to a text segment in Kalambouka et al. (2016), math dispositions of students who need support differ from those of other students, and there does not appear to be a consistent pattern. The use of the word 'challenge' in relation to inclusive classrooms highlights both the motivation of the study and the underlying values of the expected achievement within an inclusive classroom.

Specific areas, such as the calculation of fractions (Fuchs et al., 2015) or teaching students with learning difficulties, are highlighted and motivated by how the students are affected by or related to goal orientation (Schwab \& Hessels, 2015) and hence related to expected achievement in mathematics.

Risk factors for experiencing learning problems are used as metadata in a text segment that attempts to generate generalisable results, questioning whether special support is useful for developing numeracy skills, thus representing a form of expected achievement. However, the results were not generalisable because the students with risk factors who were given support did not achieve their goals to any greater degree than students with the same risk factors who were not given support (Dempsey, Valentine, \& Colyvas, 2016).

A segment from Dandy et al. (2015) illuminated the growing evidence for ethnic group differences in academic achievement among Australian students. That segment presented teachers' and students' perceptions and expectations concerning minority students in Australian schools, with a particular focus on Aboriginal and Asian students. The segment reveals consistency with community stereotypes and describes the potential implications of these stereotypes for students' school achievement, especially the negative academic expectations on Aboriginal students and how these might be deleterious to these students' performance. Hence, an assumption is made that achievement is a valuable way to measure differences between ethnic groups.

This direction of intentionality towards expected mathematical achievement also contains expressions that scrutinise and problematise the measurement of achievement and gaps in achievement between students in need or with disabilities and normally achieving students (Schulte \& Stevens, 2015; Thurlow, Wu, Lazarus, \& Ysseldyke, 2016).

To conclude, the connections among the themes of student learning and/or expected achievement in mathematics indicate a direction of intentionality towards students enhanced mathematical achievement. 


\subsection{The direction of intentionalities towards every student's learning}

The themes generating this direction were the outcome of educational practice regarding organisational structures, education policy, equity, and democracy. In all of these themes, every student's right to learn is in focus on a sociopolitical level. Themes concerning the teachers' assignment, competence, and work are connected to the outcome of educational practices, with an emphasis on equity and every student's right to learn. We describe this as a third direction. It revolves around the value assumption that all students can learn and that there is sociopolitical value to promoting such an assumption. Intentionalities are then directed towards every student's learning and with a desired impact of mathematics education on society and democracy.

Segments of texts within this direction clearly value relational solutions and performing analyses in several layers, often problematising the competence of both teachers and the school-system. One example is a segment that relates to who the students in need are and the influence of the students' attributed special needs label (Kalambouka et al., 2016; Schwab \& Hessels, 2015). Other text segments emphasise methodological aspects; for example, VanDerHeyden and Codding (2015) illuminated scholars' request for finer-grained analyses in order to better evaluate whether an intervention offers an advantage over existing practice or not.

Text segments in this direction display critical or sociopolitical values, such as how teaching in mathematics or transitions between phases in the school system exclude groups of students from present or further learning or create gaps between students (Akos, Roderick, \& Orthner, 2015; Dandy et al., 2015; Eichhorn, 2016; Morgan, Farkas, Hillemeier, \& Maczuga, 2016). Further, texts within this direction hold value assumptions that there is a need to follow up on teachers' competence and mathematical achievement using studies in the everyday classroom together with a longitudinal design in order to find meaning in the studies. This kind of design is valued and assumed to validate conclusions and implications in natural settings and over time (Pfister, Moser, \& Pauli, 2015).

A text segment from Ramberg (2016) about ability grouping reported that although there is almost no evidence for positive effects of ability grouping, it is still commonly valued and used for differentiating students in Swedish secondary schools, especially in mathematics. The motives visualised in the text reveal the use of ability grouping because the underlying value assumption is that ability grouping does not promote learning or equity. This continues to provide motives for a value discussion among school policymakers related to equity in educational settings on an overall level (Ramberg, 2016). Discussion of ability grouping is also visible in expressions in a segment from a Finnish study (Ekstam, Linnanmäki, \& Aunio, 2015). This segment shows that teachers considered and argued that to "pull out of the classroom' (p.75) was the most common way to support mathematically low-performing students, although new legislation recommended otherwise. Other text segments from the same study describe how teachers have been focusing on documentation as a result of the legislation. We interpret this as a value assumption that having teachers spend time in the education environment is more effective than producing documents.

Furthermore, in the themes in this direction, assessment is depicted in terms of inclusive assessment being highly valued. Inclusive assessment in this direction derives from the idea that all students can participate and gain from their participation, in the shorter and longer perspective. A core part of this is that adaptations and adjustments are made so that the content and situation are accessible and that this is a right that every individual has. Thus, assessment is 
provided and understood as valuable for a broad and diverse range of learners, learning content, and curricula. The value assumption regarding what inclusive assessment concerns is that it is beneficial, accessible, appropriate, and covers the full breadth of the curriculum for all students. This is seen, for example, in a text segment about an examination of assessment approaches in three European countries (Douglas, McLinden, Robertson, Travers, \& Smith, 2015). We interpret this as an underlying value assumption that students with special educational needs sometimes miss out on learning because of the narrowing down of the curriculum around the topics being assessed.

To conclude, the connections among the themes of organisational structures, education policy, equity, and democracy, with a focus on equity, indicate a direction of intentionality towards every students' learning.

\section{Discussion}

The purpose of this study was to explore processes of generating knowledge in SEM research and, more specifically, to examine directions of intentionalities. In the following, we will first discuss the consequences of our theoretical assumptions. We then draw conclusions and briefly reflect on how these connect to power relations in society.

\subsection{Application of methodology}

The framework and methodology advocated in unravelling the directions of intentionalities in SEM research consisted of two theoretical approaches: the mediated meaning making in texts (Scollon, 2001) and the intentionality interpretation of meaning (Skovsmose, 2016). These theories opened the way for deconstruction of meaning through exploring value assumptions in text segments. If we had instead approached the articles as independent pieces of meaning making, that would have generated more of an ordinary review with a content analysis of different research. Instead, we ended up with a snapshot displaying value assumptions that are socially fabricated in the SEM field. One segment of text can express more than one value assumption that, in turn, might be referred to different themes. On these occasions, connections emerged clearly between themes, while at other times, the connections were more implicit. One challenge was that a text segment's length could vary largely from one sentence to several. Here, we had to rely on the content of the text segment making sense, so it had to contain enough information to hold value assumptions. While this might have been further clarified beforehand, it was really something that was only detected during the analysis. In the results and analysis, we have focused on how value assumptions are used in text segments. This is mirrored by our strategy for selection and our method of analysis. Our understanding and application of the concept of value assumptions has contributed with a broad understanding of what segments might be included. This can be perceived as both a strength and a weakness of this study. The strength is that many hopes, fears, desires, etc. could fit in, and we did not direct or limit what could count as valued. At the same time, many of the identified segments actually expressed similar value assumptions. This could depend on two things: (1) that we in our cultural and discursive situatedness in research do not see other things than we can imagine ourselves or (2) that the field does indeed contain some fairly stable and persistent value assumptions. 


\subsection{Positioning of our own value assumptions}

Another challenge was being distinct about our own positioning. Because we analysed the direction of intentionality - and because we have made an interpretative framework and analysis - there was urgency and responsibility to make our own intentionality and perspective visible. We believe that Skovsmose's (2016) claim about research as not being value free is important when writing and reading research. That includes our own research but also our own value assumptions and meanings that are situated in culture, context, history, and the like. Therefore, we made an effort to express our history and positioning with regard to value assumptions, allowing readers to analyse our work accordingly. In retrospect, we believe that our way of understanding and interpreting research has influenced the choice of theory. The chosen theory focuses on sociopolitical and relational aspects and not on, for example, mathematical content or constructions. Secondly, we think that the themes found could have been the same, regardless of theory. The connections, on the other hand, are influenced by the theoretical choice. A researcher who derives from other theoretical perspectives, such as constructivism, would probably make other connections. Thirdly, our own value assumptions as researchers are visible in the analytical work; for example, a view of the disabled learner as having rights and valuable knowledge and teaching as connected to democratic values and what kind of society we value. In summary, the power we exert stems primarily from limitations caused by our ontological underpinnings and choice of theory. However, we fully recognize that what we have found is not the truth but just some of many possible narratives and directions of intentionalities. In addition, we aimed to display the meaning making that we are part of as researchers in this field and reflect upon the possible consequences for SEM research and practice.

\subsection{Conclusions of results}

While our analysis shows a direction towards every student's learning, there are still only a few articles concerning students with major disabilities. Text segments also lack students' perspective. We agree with Lambert (2015), who concluded that 'Mathematics education must include disability in calls for equity, as well as include learners with disabilities in research' (p.15). A similar tendency is also seen in a review of the notion of inclusion in mathematics education research, where Roos (2019, p. 25) concluded that we must 'take students' voices into consideration'. One conclusion is that SEM research indicates that the teacher must always be responsible for and have competence of how to support and maintain high-quality teaching. This in turn implies a widening of teachers' traditional teaching competences, to also include cooperation with other professions and competent delegation of educational assignments to colleagues or assistants. In sum, this might be interpreted as either the teacher's competence or the role or function being sufficient. Another conclusion about the value assumptions is the depiction of other professions involved in teaching as an extension of the teachers' functions, which implies a value assumption that even having high competence is not enough for a teacher. Teachers need other teaching professionals in order to produce high-quality teaching for students in need of support. One further conclusion about the three directions and the relations between them is that there is ongoing meaning making about high achievement as something good and achievement as always better when it is increasing or has the possibility to increase. The achievement is often connected to a specific intervention that can solve the 'problem' of low achievement. 
Also, achievement is related to measures of equity and differences between students and groups of students. Thus, we wish to reconnect to Skovsmose's critical theory of the policy of meaning, of which direction of intentionality is a part. This indicates that both research and society make the value assumptions that groups of students can and should be compared by achievement. Intrinsically, this illustrates that privileged groups (i.e., students who achieve according to policy standards) are constructed as the desired students regardless of whether research actually seeks to counteract this disadvantage and privilege (compared to Halai et al., 2016). Value assumptions that are directed towards sociopolitical approaches to SEM and where issues of equity and democracy are at the core are most displayed in the direction of intentionalities towards every student's learning. We claim that when value assumptions are made that recognise success as separated from achievement or even knowledge, research seems to be able to recognise aspects of privilege and power relations and pose questions about what kind of society is desirable. Even then, and even if research also recognises its own position and power, research still contributes to the labelling and grouping of individuals.

\subsection{Concluding reflection}

To sum up, this study both derived from and resulted in the insight that there are potentially many directions of intentionality in SEM research, three of which we have identified. Our hope and aim are that these directions might display some of the multifaceted and multidisciplinary opportunities and possibilities inherent in SEM. In addition, we hope that these directions might invoke insights of many other competing or completing directions to be detected. The directions hold both limitations and strengths.

In the direction of intentionality towards the teacher and teaching competence, some useful aspects can be seen, and their nature is very much that of a two-sided coin in terms of strengths and limitations. One side of the coin could be the high valuing and appreciation of teacher competence. The need to make the competence visible in relation to the context and situation might reveal aspects of quality in SEM education. This work could be the beginning of development on a school or a way to start a useful research project. On the other side of the coin is the phenomenon of teacher blaming, which is a tendency for SEM students to lack knowledge or development mostly due to teachers not having the right kind of knowledge regarding mathematics, the students, or the methods. It is the teachers' competence that is lacking or needs to be strengthened.

In the direction of intentionality of enhanced mathematical achievement, there are strengths regarding the possibility for the teacher to be attendant towards what achievement is and how it can be promoted through teaching approaches, adaption, and/or interventions. The possibility and power in paying attention to how learning, thinking, etc. takes place for individual students is also highlighted and can promote a sustainable path forward. Here, the opportunity to recognise different ways to solve or handle problems is key, which can also be similar between SEM students and other students. A limitation in this direction is that it frames the development of knowledge in mathematics as dependent on assessment. Hence, it is important to have an awareness of assessment and its consequences and to be vigilant in the use of assessments by both teachers and researchers.

In the direction of intentionalities towards every student's learning, a strength can be seen in a positive anticipation regarding all students' learning and the will to keep and encourage this anticipation as a democratic and joint assignment for society. The vision regarding how to think about and plan for strategies and pedagogical approaches that allows for and fosters this 
joint assignment is also a strength. However, this can also be seen as a limitation since then there is a need for everyone in society to take on this assignment and agree on the direction.

Our reflections on the three directions are that there is a tension between the teachers' task to gain deep and specific knowledge in the first direction and the democratic assignment in the third direction. These two must be linked. Teacher competence cannot be the responsibility of one teacher alone but is also the responsibility of an organisation and the research community. If cooperation does not take place, conclusions from assessments - as shown in the second direction - might be drawn that SEM students are in a specific state that is too hard or not possible to develop from or change. These students might have their future participation in society hindered.

All this implies a need for a diverse knowledge base in supporting students in need of support in mathematics. Therefore, it is essential to have collaboration between researchers from different fields or disciplines and between traditions and methods as well as with the educational practice and teachers.

We stress the importance of recognising many truths, kinds of knowledge, and avenues of approach in SEM research in order to explain and understand the challenging moments in the teaching and learning of mathematics. The three directions contribute to visualising the diversity of understandings of what SEM is and can be and what comes into play through value assumptions. Hence, reflecting upon directions of intentionality makes it possible to take the many facets into account and to reflect upon them when applying results from research both to further research and to practice. There is still a need to put these insights from research and evidence-based practice into the local and national contexts because, as Skovsmose (2016) stressed, the intentionality interpretation of meaning is 'structured by economic, political, cultural, and discursive factors' (p. 411). In addition, the direction of intentionality is not only socially structured but also personally structured because it is situated in real life and therefore directs action and thinking (Skovsmose, 2016). To reflect upon one's own and others' value assumptions and intentionality about teacher and teaching competence, mathematical achievement and every student's learning might potentially guide professionals to enhance multifaceted reflection, discussion, and knowledge production.

Funding Information Open access funding provided by Örebro University.

\section{Compliance with ethical standards}

Conflict of interest The authors declare that they have no conflict of interest.

\section{Appendix}

The meaning(s) of special education mathematics.

\section{Anette Bagger, Helena Roos \&Margareta Engvall.}

References mentioned in the result are marked with *. The following 53 articles have been used for analysis

*Akos, P. R., Roderick A., \& Orthner, D. (2015). Sociodemographic moderators of middle school transition effects on academic achievement. Journal of Early Adolescence, 35(2), 170198. 
Anderson, A. (2015). Dance/movement therapy's influence on adolescents' mathematics, social-emotional, and dance skills. Educational Forum, 79(3), 230-247.

*Bakker, M., Van den Heuvel-Panhuizen, M., \& Robitzsch, A. (2016). Effects of mathematics computer games on special education students' multiplicative reasoning ability. British Journal of Educational Technology, 47(4), 633-648.

Bottge, B.A., Toland, M.D., Gassaway, L., (...), Griffen, A.K., \& Ma, X. (2015). Impact of enhanced anchored instruction in inclusive math classrooms. Exceptional Children, 81(2), 158-175.

*Calderón-Tena, C. O. (2016). Mathematical development: The role of broad cognitive processes. Educational Psychology in Practice, 32(2), 107-121.

*Dandy, J., Durkin, K., Barber, B., \& Houghton, S. (2015). Academic expectations of Australian students from Aboriginal, Asian and Anglo backgrounds: Perspectives of teachers, trainee-teachers and students. International Journal of Disability, Development and Education, 62(1), 60-82.

*Dempsey, I., Valentine, M., \& Colyvas, K. (2016). The effects of special education support on young Australian school students. International Journal of Disability, Development and Education, 63(3), 271-292.

*Depountis, V.M., Pogrund, R.L., Griffin-Shirley, N., \& Lan, W.Y. (2015). Technologies that facilitate the study of advanced mathematics by students who are blind: Teachers' perspectives. International Journal of Special Education, 30(2), 131-144.

*Douglas, G., McLinden, M., Robertson, C., Travers, J., \& Smith, E. (2015). Including pupils with special educational needs and disability in national assessment: Comparison of three country case studies through an inclusive assessment framework. International Journal of Disability, Development and Education, 63(1), 98-121.

*Eichhorn, M. S. (2016). Haunted by math: the impact of policy and practice on students with math learning disabilities in the transition to post-secondary education in Mumbai, India. Global Education Review, 3(3), 75-93.

*Ekstam, U., Linnanmäki, K., \& Aunio, P. (2015). Educational support for low-performing students in mathematics: the three-tier support model in Finnish lower secondary schools. European Journal of Special Needs Education, 30(1), 75-92.

Ekstam, U., Korhonen, J., Linnanmäki, K., \& Aunio, P. (2017). Special education preservice teachers' interest, subject knowledge, and teacher efficacy beliefs in mathematics. Teaching and Teacher Education,63, 338-345.

*Fien, H., Doabler, C., Nelson, N., Kosty, D., Clarke, B., \& Baker, S. (2015). An examination of the promise of the NumberShire Level 1 gaming intervention for improving student mathematics outcomes. Journal of Research on Educational Effectiveness, 9(4), 635661 .

*Fuchs, L. S., Fuchs, D., Compton, D. L., Wehby, Jo., Schumacher, R. F., Gersten, R., \& Jordan, N. C. (2015). Inclusion versus specialized intervention for very-low-performing students: What does "access" mean in an era of academic challenge? Exceptional Children, 81(2), 134-157.

*Gunarhadi, S., Anwar, M., Andayani, T. R., \& Shaari, A. S. (2016). The effect of clusterbased instruction on mathematic achievement in inclusive schools. International Journal of Special Education, 31(1), 78-87.

*Hinton, V., Flores, M., Burton, M., \& Curtis, R. (2015). An investigation into pre-service special education teachers' mathematical skills, self-efficacy, and teaching methodology. Issues in the Undergraduate Mathematics Preparation of School Teachers, 1, 1-13. 
Holopainen, L., Taipale, A., \& Savolainen, H. (2017). Implications of overlapping difficulties in mathematics and reading on self-concept and academic achievement. International Journal of Disability, Development and Education, 64(1), 88-103.

Hord, C., \& Xin, Y. P. (2015). Teaching area and volume to students with mild intellectual disability Journal of Special Education, 49,(2), 118-128.

Hord, C., Tzur, R., Xin, Y.P., Si, L., Kenney, R.H., \& Woodward, J. (2016). Overcoming a 4th grader's challenges with working-memory via constructivist-based pedagogy and strategic scaffolds: Tia's solutions to challenging multiplicative tasks. Journal of Mathematical Behavior, 44, 13-33.

Hotulainen, R., Mononen, R., \& Aunio, P. (2016). Thinking skills intervention for low achieving first graders. European Journal of Special Needs Education, 31(3), 360-375.

*Hunt, J. H., Valentine, C., Bryant, D. P., Pfannenstiel, K. H., \& Bryant, B. R. (2016). Supplemental mathematics intervention: How and why special educators intensify intervention for students with learning disabilities. Remedial and Special Education, 37(2), 78-88.

*Hunt, J. H., Tzur, R., \& Westenskow, A. (2016). Evolution of unit fraction conceptions in two fifth-graders with a learning disability: an exploratory study. Mathematical Thinking and Learning, 18(3), 182-208.

*Jitendra, A., Nelson, G., Pulles, S., Kiss, A., \& Houseworth, J. (2016). Is mathematical representation of problems an evidence-based strategy for students with mathematics difficulties? Exceptional Children, 83(1), 8-25.

Johansen, V., \& Somby, H. M., (2016). Does the "pupil enterprise programme" influence grades among pupils with special needs? Scandinavian Journal of Educational Research, 60(6), 736-745.

*Kalambouka, A., Pampaka, M., Omuvwie, M., \& Wo, L. (2016). Mathematics dispositions of secondary school students with special educational needs. Journal of Research in Special Educational Needs, 16, 701-707.

*Kim, Y., Thayne, J., \& Wei, Q. (2017). An embodied agent helps anxious students in mathematics learning. Educational Technology Research and Development, 65(1), 219-235.

Kohli, N., Sullivan, A. L., Sadeh, S., \& Zopluoglu, C. (2015). Longitudinal mathematics development of students with learning disabilities and students without disabilities: A comparison of linear, quadratic, and piecewise linear mixed effects models. Journal of School Psychology, 53(2), 105-120.

Kyriakides, A. O., \& Houssart, J. (2016) Paraprofessionals in Cyprus and England: Perceptions of their role in supporting primary school mathematics. Research in Mathematics Education, 18(3), 249-266, DOI: 10.1080/14794802.2016.1189352

Lambert, R. (2015). Constructing and resisting disability in mathematics classrooms: a case study exploring the impact of different pedagogies. Educational Studies in Mathematics, 89(1), 1-18.

Lambert, R., \& Sugita, T. (2016). Increasing engagement of students with learning disabilities in mathematical problem-solving and discussion. Support for Learning, 31(4), 347-366.

*Marschark, M., Shaver, D., Nagle, K., \& Newman, L. (2015). Predicting the academic achievement of deaf and hard-of-hearing students from individual, household, communication, and educational factors. Exceptional Children, 81(3), 350-369.

*McDaniel, S. C., Houchins, D. E., \& Robinson, C. (2016). The effects of check, connect, and expect on

behavioral and academic growth. Journal of Emotional and Behavioral Disorders, 24(1), $42-53$. 
*Mekonnen, M., Hannu, S., Elina, L., \& Matti, K. (2016). The self-concept of deaf/hard-of-hearing and hearing students. Journal of Deaf Studies and Deaf Education, 21(4), 345-351.

*Morgan, P. L., Farkas, G., Hillemeier, M. M., \& Maczuga, S. (2016). Who is at risk for persistent mathematics difficulties in the United States? Journal of Learning Disabilities, 49(3), 305-319.

*Moscardini, L. (2015). Primary special school teachers' knowledge and beliefs about supporting learning in

numeracy. Journal of Research in Special Educational Needs, 15(1), 37-47.

*Murphy, M. R., \& Marshall, K. J. (2015). Common core preparation in special education teacher education programs: Beginning the conversation. Teacher Education and Special Education, 38(3), 167-185.

*Peltier, C., \& Vannest, K. (2016). Schema-based strategy instruction and the mathematical problem-solving performance of two students with emotional or behavioral disorders. Education and Treatment of Children, 39(4), 521-543.

*Pfister, M., Moser O. E., \& Pauli, C. (2015). Scaffolding for mathematics teaching in inclusive primary classrooms: a video study. ZDM: The International Journal on Mathematics Education, 47(7), 1079-1092.

*Powell, S. R. (2015). Connecting evidence-based practice with implementation opportunities in special education mathematics preparation. Intervention in School and Clinic, 51(2), 90-96.

*Radford, J., Bosanquet, P., Webster, R., \& Blatchford, P. (2015). Scaffolding learning for independence:

Clarifying teacher and teaching assistant roles for children with special educational needs. Learning and Instruction, 36, 1-10.

*Ramberg, J. (2016). The extent of ability grouping in Swedish upper secondary schools: a national survey.

International Journal of Inclusive Education, 20(7), 685-710.

*Scammacca, N. K., Fall, A-M., \& Roberts, G. (2015). Benchmarks for expected annual academic growth for students in the bottom quartile of the normative distribution. Journal of Research on Educational Effectiveness, 8(3), 366-379.

*Schulte, A., \& Stevens, J. (2015). Once, sometimes, or always in special education. Exceptional Children,

81(3), 370-387.

*Schwab, S., \& Hessels, M. G. P. (2015). Achievement goals, school achievement, selfestimations of school achievement, and calibration in students with and without special education needs in inclusive education.

Scandinavian Journal of Educational Research, 59(4), 461-477.

Shifrer, D. (2016). Stigma and stratification limiting the math course progression of adolescents labeled with a learning disability. Learning and Instruction, 42, 47-57.

Shin, M., \& Bryant, D. P. (2015). Fraction interventions for students struggling to learn mathematics: a research synthesis. Remedial and Special Education, 36(6), 374-387.

Stone, S., \& Uretsky, M. (2015). School correlates of academic behaviors and performance among McKinney-Vento identified youth. Urban Education, 51(6), 600-628.

*Thai, L. K., \& Yasin, M. H. M. (2016). Magic finger teaching method in learning multiplication facts among deaf students. Journal of Education and Learning, 5(3), 40-50. 
*Thurlow, M., Wu, Y., Lazarus, S., \& Ysseldyke, J. (2016). Special education-non-special education achievement gap in math: Effects of reporting methods, analytical techniques, and reclassification. Exceptionality, 24(1), 32-44.

*VanDerHeyden, A. M., \& Codding, R. S. (2015). Practical effects of classwide mathematics intervention. School Psychology Review, 44(2), 169-190.

*Van Ingen, S., Eskelson, S. L., \& Allsopp, D. (2016). Evidence of the need to prepare prospective teachers to engage in mathematics consultations. Mathematics Teacher Education and Development, 18(2), 73-91.

Weiland, C. (2016). Impacts of the Boston prekindergarten program on the school readiness of young children with special needs. Developmental Psychology, 52(11), 1763-1776.

Witmer, S. E., Cook, E., Schmitt, H., \& Clinton, M. (2015) The read-aloud accommodation during instruction: Exploring effects on student self-perceptions and academic growth. Learning Disabilities: A Contemporary Journal, (13)1, 95-109.

Open Access This article is licensed under a Creative Commons Attribution 4.0 International License, which permits use, sharing, adaptation, distribution and reproduction in any medium or format, as long as you give appropriate credit to the original author(s) and the source, provide a link to the Creative Commons licence, and indicate if changes were made. The images or other third party material in this article are included in the article's Creative Commons licence, unless indicated otherwise in a credit line to the material. If material is not included in the article's Creative Commons licence and your intended use is not permitted by statutory regulation or exceeds the permitted use, you will need to obtain permission directly from the copyright holder. To view a copy of this licence, visit http://creativecommons.org/licenses/by/4.0/.

\section{References}

All references marked with an $*$ are articles included in the review and analysis

*Akos, P. R., Roderick A., \& Orthner, D. (2015). Sociodemographic moderators of middle school transition effects on academic achievement. Journal of Early Adolescence, 35(2), 170-198.

Bagger, A., \& Roos, H. (2015). How research conceptualises the student in need of special education in mathematics. In O. Helenius, A. Engström, T. Meaney, P. Nilsson, E. Norén, J. Sayers \& M. Österholm (red.), Development of Mathematics Teaching: Design, Scale, Effects. (pp. 27-36). Proceedings of MADIF9: The Ninth Swedish Mathematics Education Research Seminar, Umeå, February 4-5, 2014. Linköping, Sweden: SMDF.

Bagger, A., Roos, H., \& Engvall, M. (2018). Investigating the politics of meaning(s) in Nordic research on special education mathematics: developing a methodology. In J. Häggström, Y. Liljekvist, J. Bergman Ärlebäck, M. Fahlgren, \& O. Olande (Eds.), Perspectives on professional development of mathematics teachers. Proceedings of MADIF 11 (pp. 141-150). Gothenburg, Sweden: SMDF.

*Bakker, M., Van den Heuvel-Panhuizen, M., \& Robitzsch, A. (2016). Effects of mathematics computer games on special education students' multiplicative reasoning ability. British Journal of Educational Technology, 47(4), 633-648.

*Calderón-Tena, C. O. (2016). Mathematical development: The role of broad cognitive processes. Educational Psychology in Practice, 32(2), 107-121.

*Dandy, J., Durkin, K., Barber, B., \& Houghton, S. (2015). Academic expectations of Australian students from Aboriginal, Asian and Anglo Backgrounds: Perspectives of Teachers, trainee-teachers and students. International Journal of Disability, Development and Education, 62(1), 60-82.

*Dempsey, I., Valentine, M., \& Colyvas, K. (2016). The effects of special education support on young Australian school students. International Journal of Disability, Development and Education, 63(3), 271-292.

*Depountis, V.M., Pogrund, R.L., Griffin-Shirley, N., \& Lan, W.Y. (2015). Technologies that facilitate the study of advanced mathematics by students who are blind: Teachers' perspectives. International Journal of Special Education, 30 (2), 131-144. 
*Douglas, G., McLinden, M., Robertson, C., Travers, J., \& Smith, E. (2015). Including pupils with special educational needs and disability in national assessment: Comparison of three country case studies through an inclusive assessment framework. International Journal of Disability, Development and Education, 63(1), 98-121.

*Eichhorn, M. S. (2016). Haunted by Math: the impact of policy and practice on students with math learning disabilities in the transition to post-secondary education in Mumbai, India. Global Education Review, 3(3), 75-93.

*Ekstam, U., Linnanmäki, K., \& Aunio, P. (2015). Educational support for low-performing students in mathematics: the three-tier support model in Finnish lower secondary schools. European Journal of Special Needs Education, 30(1), 75-92.

Ernest, P. (2016). Mathematics and values. In B. Larvor (Ed.), Mathematical Cultures. Trends in the History of Science (pp. 189-214). Basel, Switzerland: Birkhäuser.

*Fien, H., Doabler, C., Nelson, N., Kosty, D., Clarke, B., \& Baker, S. (2015). An examination of the promise of the NumberShire Level 1 gaming intervention for improving student mathematics outcomes. Journal of Research on Educational Effectiveness, 9(4), pp. 635-661.

*Fuchs, L. S., Fuchs, D., Compton, D. L., Wehby, J., Schumacher, R. F., Gersten, R., \& Jordan, N. C. (2015). Inclusion versus specialized intervention for very-low-performing students: What does 'access' mean in an era of academic challenge? Exceptional Children, 81(2), 134-157.

*Gunarhadi, S., Anwar, M., Andayani, T. R., \& Shaari, A. S. (2016). The effect of cluster-based instruction on mathematic achievement in inclusive schools. International Journal of Special Education, 31(1), $78-87$.

Halai, A., Muzaffar, I., \& Valero, P. (2016). Research rationalities and the construction of the deficient multilingual learner. In R. Barwell et al. (Eds.), Mathematics Education and Language Diversity. Nww ICME Study Series. Cham, Switzerland: Springer.

Heyd-Metzuyanim, E. (2013). The co-construction of learning difficulties in mathematics-teacher-student interactions and their role in the development of a disabled mathematical identity. Educational Studies in Mathematics, 83(3), 341-368.

*Hinton, V., Flores, M., Burton, M., \& Curtis, R. (2015). An investigation into pre-service special education teachers' mathematical skills, self-efficacy, and teaching methodology. Issues in the Undergraduate Mathematics Preparation of School Teachers, 1, 1-13.

*Hunt, J., Tzur, R., \& Westenskow, A. (2016). Evolution of unit fraction conceptions in two fifth-graders with a learning disability: an exploratory study. Mathematical Thinking and Learning, 18(3), 182-208.

*Hunt, J. H., Valentine, C., Bryant, D. P., Pfannenstiel, K. H., \& Bryant, B. R. (2016). Supplemental mathematics intervention: How and why special educators intensify intervention for students with learning disabilities. Remedial and Special Education, 37(2), 78-88.

*Jitendra, A., Nelson, G., Pulles, S., Kiss, A., \& Houseworth, J. (2016). Is mathematical representation of problems an evidence-based strategy for students with mathematics difficulties? Exceptional Children, 83(1), 8-25.

*Kalambouka, A., Pampaka, M., Omuvwie, M., \& Wo, L. (2016). Mathematics dispositions of secondary school students with special educational needs. Journal of Research in Special Educational Needs, 16, 701-707.

*Kim, Y., Thayne, J., \& Wei, Q. (2017). An embodied agent helps anxious students in mathematics learning. Educational Technology Research and Development, 65(1), 219- 235.

Lambert, R. (2015). Constructing and resisting disability in mathematics classrooms: a case study exploring the impact of different pedagogies. Educational Studies in Mathematics, 89(1), 1-18.

Magne, O. (2006). Historical aspects on special education in mathematics. Nordic Studies in Mathematics Education, 11(4), 7-35.

*Marschark, M., Shaver, D., Nagle, K., \& Newman, L. (2015). Predicting the academic achievement of deaf and hard-of-hearing students from individual, household, communication, and educational factors. Exceptional Children, 81(3), 350-369.

*McDaniel, S. C., Houchins, D. E., \& Robinson, C. (2016). The effects of check, connect, and expect on behavioral and academic growth. Journal of Emotional and Behavioral Disorders, 24(1), 42-53.

*Mekonnen, M., Hannu, S., Elina, L., \& Matti, K. (2016). The self-concept of deaf/hard-of-hearing and hearing students. Journal of Deaf Studies and Deaf Education, 21(4), 345-351.

*Morgan, P. L., Farkas, G., Hillemeier, M. M., \& Maczuga, S. (2016). Who is at risk for persistent mathematics difficulties in the United States? Journal of Learning Disabilities, 49(3), 305-319.

* Moscardini, L. (2015). Primary special school teachers' knowledge and beliefs about supporting learning in numeracy. Journal of Research in Special Educational Needs, 15(1), 37-47.

*Murphy, M. R., \& Marshall, K. J. (2015). Common core preparation in special education teacher education programs: Beginning the conversation. Teacher Education and Special Education, 38(3), 167-185.

Norris, S., \& Jones, R. H. (Eds.). (2005). Discourse in action: introducing mediated discourse analysis. London, UK: Routledge. 
*Peltier, C., \& Vannest, K. (2016). Schema-based strategy instruction and the mathematical problem-solving performance of two students with emotional or behavioral disorders. Education and Treatment of Children, 39(4), 521-543.

*Pfister, M., Moser O. E., \& Pauli, C. (2015). Scaffolding for mathematics teaching in inclusive primary classrooms: a video study. ZDM: The International Journal on Mathematics Education, 47(7), 1079-1092.

*Powell, S. R. (2015). Connecting evidence-based practice with implementation opportunities in special education mathematics preparation. Intervention in School and Clinic, 51(2), 90-96.

*Radford, J., Bosanquet, P., Webster, R., \& Blatchford, P. (2015). Scaffolding learning for independence: Clarifying teacher and teaching assistant roles for children with special educational needs. Learning and Instruction, 36, 1-10.

*Ramberg, J. (2016). The extent of ability grouping in Swedish upper secondary schools: A national survey. International Journal of Inclusive Education, 20(7), 685-710.

Roos, H. (2019). Inclusion in mathematics education: an ideology, a way of teaching, or both? Educational Studies in Mathematics education, 100(1), 25-41.

*Scammacca, N. K., Fall, A-M., \& Roberts, G. (2015). Benchmarks for expected annual academic growth for students in the bottom quartile of the normative distribution. Journal of Research on Educational Effectiveness, 8(3), 366-379.

Scherer, P., Beswick, K., DeBlois, L., Healy, L., \& Moser Opitz, E. (2016). Assistance of students with mathematical learning difficulties: How can research support practice? - A summary. ZDM: the International Journal on Mathematics Education, 48(5), 249-259.

Schmidt, M. C. S. (2016). Dyscalculia $\neq$ maths difficulties. An analysis of conflicting positions at a time that calls for inclusive practices. European Journal of Special Needs Education, 31(3), 407-421.

*Schulte, A., \& Stevens, J. (2015). Once, sometimes, or always in special education. Exceptional Children, 81(3), 370-387.

*Schwab, S., \& Hessels, M. G. P. (2015). Achievement goals, school achievement, self-estimations of school achievement, and calibration in students with and without special education needs in inclusive education. Scandinavian Journal of Educational Research, 59(4), 461-477.

Scollon, R. (2001). Mediated discourse: the nexus of practice. New York, NY: Routledge.

Scollon, R., \& Scollon, S. (2009). Breakthrough into action. Text \& Talk, 29(3), 277-294.

Scotland, J. (2012). Exploring the philosophical underpinnings of research: Relating ontology and epistemology to the methodology and methods of the scientific, interpretive, and critical research paradigms. English Language Teaching, 5(9), 9-16. https://doi.org/10.5539/elt.v5n9p9

Skovsmose, O. (2016). An intentionality interpretation of meaning in mathematics education. Educational Studies in Mathematics, 92(3), 411-424.

*Thai, L. K. \& Yasin, M. H. M. (2016). Magic finger teaching method in learning multiplication facts among deaf students. Journal of Education and Learning, 5(3), 40-50.

*Thurlow, M., Wu, Y., Lazarus, S., \& Ysseldyke, J. (2016). Special education - non-special education achievement gap in math: Effects of reporting methods, analytical techniques, and reclassification. Exceptionality, 24(1), 32-44.

*Van Ingen, S., Eskelson, S. L., \& Allsopp, D. (2016). Evidence of the need to prepare prospective teachers to engage in mathematics consultations. Mathematics Teacher Education and Development, 18(2), 73-91.

*VanDerHeyden, A. M., \& Codding, R. S. (2015). Practical effects of classwide mathematics intervention. School Psychology Review, 44(2), 169-190.

Publisher's note Springer Nature remains neutral with regard to jurisdictional claims in published maps and institutional affiliations. 